\title{
Influence of Labor Transfer on Rural Households Coal Consumption
}

\author{
Wang Ping, Zhu Min, Zheng Yanan, Gu Jingge \\ School of Management, Xi'an University of Science and Technology, Xi'an, China
}

Email address:

420199253@qq.com (Wang Ping), 1192420001@qq.com (Zhu Min),3446514@qq.com (Zheng Yanan), 1006953361@qq.com (Gu Jingge)

To cite this article:

Wang Ping, Zhu Min, Zheng Yanan, Gu Jingge. Influence of Labor Transfer on Rural Households Coal Consumption. Journal of Energy and Natural Resources. Vol. 6, No. 1, 2017, pp. 8-13. doi: 10.11648/j.jenr.20170601.12

Received: January 25, 2017; Accepted: February 8, 2017; Published: March 28, 2017

\begin{abstract}
With the development of economic in rural area, the increase number of labor transfer made farmers' income more and more, and the energy consumption especially the coal has also changed constantly. Using the data of "Labor Migration and rural life energy survey" in Shannxi province, by the Tobit regression model to analyze that the influence of labor transfer on rural households coal consumption. The results show that the increasing number of labor transfer made the household coal consumption significantly decreased. The increase of labor transfer raises the household coal consumption; The proportion of labor transfer income to family income shows negative relation with the farmers' coal consumption. Finally, some useful suggestions on how to raising farmers' income and energy usage, thus promoting the continuous development of new countryside construction.
\end{abstract}

Keywords: Rural Area, Labor Transfer, Labor Transfer Income, Coal Consumption

\section{Introduction}

With the advancement of science and technology, the level of agricultural mechanization has been improved continuously, and a great number of surplus labor force has appeared in rural areas [1]. With the development of industrialization and modernization, more and more rural labor force has entered in the urban labor market. People's Ministry data show that the total number of rural migrant workers reached 273.95 million in 2014, the data is 501 million larger than that in 2010, of which migrant workers reached 168.21 million, and the average wage of migrant workers, up 9.8 percent from 2013. With the rapid development of the national economy, China's coal consumption has grown each year and had the largest share of total energy consumption. [2] Transport facilities, the opening of the energy supply channels are a growing part of the total energy consumption. [3] [4] Based on the correlation study of labor transfer and so on aspects elaborated as follows:

Firstly, there has more research on the transfer of labor, the current transfer of labor is basically choose to make money in the city, back to rural consumption patterns, the phenomenon of "move without moving" is obviously [5]. In recent years, the overall education level of China's population has been greatly improved, to promote employment opportunities and improve the mobility of the population greatly [6]. Stark [7] and others think that the transfer of labor in the family will drive the family's overall income. The shift in labor forces brings higher income levels to households, and higher incomes make them more spending power [8]. These studies focus on the causes of labor migration and the impact of labor migration on the overall economic situation, but there has few research on the impact of transfer on individual household members or individual households, and the study on household consumption of coal has important significance.

Secondly, there are many studies on farmers' consumption of coal, mainly concentrating on the influence factors of farmer's energy consumption and coal consumption have negative impact on environment. Family economic status, family size and occupation of household heads and other factors can greatly affect the energy consumption of rural households, Cheng Chuan's research shows that the family income have significant negative impact on the household biomass energy consumption; Lou Bojie [9] proves that the economic levels of economic not only affects the energy consumption of peasant households, but also determines the consumption structure of peasant household energy consumption; Wang Xiaohua thinks that rural per capita income has a significant positive impact on per capita energy 
consumption. Foley [10] argues that farmers are accustomed to obtain material from local sources; the shift in energy consumption structure is mainly determined by the available resources in local resources, farmers far away from the woodland, the firewood on the energy consumption is decrease, and consumption of coal is increase. [11] The price of coal is also an important factor affecting the energy consumption of coal household goods. In addition, coal is still some questions on its utilization such as low utilization rate, under-developed utilization method, serious waste made environment problem increasing out-standing. On the assumption that total coal resources remain equal, more coal consumption also led to increasing in greenhouse gas and pollution emissions. [12] and had a negative impact on the rural environment. Although there are many studies on the factors affecting energy consumption, there are few studies on the labor force transfer.

Finally, research on the influence of labor transfer to farmers' coal consumption is scarce. Increase of income, the improvement of living standard and the change of consumption consciousness brought by rural labor transfer which will directly or indirectly affect and change the rural people's energy consumption structure. Labor transfer improved the income level of the family, the higher income resulting in higher consumption capacity [7]. Higher the family income is, more energy consumption demand is [10]. Non-agricultural employment affects the decision of farmers' energy consumption increased household income, which in turn stimulated farmers' energy consumption. Zhang Cuiping [13] thinks that non-agricultural employment will influence household energy consumption through the labor force and income effects. Guoxin [14] thinks that the transfer of labor have a significant impact on farmer's commercial energy consumption such as electricity and coal and so on. However, Up to now, the research on labor transfer and household coal consumption have been still blank.

Coal has great important status in Shaanxi, and coal has also played an important role in the farmers' energy consumption. Coal resources are rich in Shaanxi. In addition, with the demand for heating in winter, which could increase families' coal utilization. Using the data of "labor migration and rural energy survey" in Shaanxi province, Using some variables such as household economic characteristics to analyze that how the labor transfer affects the coal consumption in rural households, in order to suggestions for improving farmers' income and energy usage, making policy for the construction and development of new countryside. Based on the status quo and development trend of rural labor transfer and energy consumption, this paper puts forward the following conclusions: (1) Does labor transfer affect farmer's consumption? (2) How does labor transfer affect farmers' coal consumption?

\section{Data and Methods}

(I) Data sources

The data in this paper mainly comes from the sample survey of rural labor energy transfer and rural living energy in Shaanxi province in June, 2013. The survey is divided into three parts: 1) family and personal basic information; 2) the transfer of family labor; 3) household energy consumption. The research object of the study are the farmers in Shaanxi province. Taking households as basic unit and adopting the method of asking and questioning. The questionnaire ranged over a wide locations, which includes Xianyang, Yan'an, Hanzhong and Tongchuan. The questionnaire reflects the actual situation of Shaanxi rural labor transfer and rural household energy consumption to some extent. This investigation altogether provides questionnaire 300, the actual recovery of 290 copies, of which 288 valid questionnaires, for an effective questionnaire returns-ratio is $96 \%$.

(II) Model and variable settings

According to the previous studies on coal consumption, the main factors affecting the coal consumption are household head, family size, energy price [9], net income per capita [15], household education level, energy availability [9], Consumption preference [16]. In this paper, transfer of labor is the independent variable. Transfer of labor is measured by labor transfer income, the amount of transferring people, the proportion of transfer income to household income, other variables are control variables, to analysis the impact of labor transfer on household consumption of coal.

(1) dependent variable

The dependent variable is the farmer's coal consumption, that is, the household annual per capita coal consumption [14]. per capita refers to the population of per capita household resident.

(2) Independent variables

The independent variable is labor transfer. Along the course of analysis, this paper uses three indicators, including the number of labor force transfer [15], the per capita labor force transfer income and the proportion of labor transfer in the total household income as a whole. The number of labor force transfer refers to the number of family members who out for work. The per capita labor transfer income refer to the ratio of total number of farmer workers to the population of household resident. The proportion of labor transfer income refers to the ratio of migrant money to the total family income. [16]

(3) Control variables

The education levels of the householder are coded as follows [17]: $0=$ illiteracy, $6=$ primary school, $9=$ junior high school, 12=high school, 14= secondary vocational school, $16=$ college and above; The work of the householder is coded into three categories: $1=$ agricultural labor, $2=$ out-migrating for work, $3=$ local non-agricultural industries. Energy price: the main price factor in this paper includes coal and electricity prices, coal prices. The price of coal is the price of coal per kilogram in household life, electricity price is the per kilowatt hour of the rural power grid. The annual per capita net income of agriculture; family size: This paper uses the family resident population to measure the size of the family population; Energy availability: using per capita arable land to measure farmers' energy acquirement; Consumer Preference: respondents to use the energy in their daily life on behalf of 
the consumer.

(III) Research methods

The study uses the Tobit regression model, the dependent variable of the model has the characteristics of partial continuous and partial discrete distribution. In this paper, coal consumption of farmers in Shaanxi Province meet the conditions of using Tobit regression analysis. Statistical analysis was performed using stata 10.0 .

\section{Results and Discussion}

(I) Results
(1) Descriptive results

Table 1 shows the mean, standard deviation, maximum and minimum values for each variable. The results show that each household has a labor transfer, the majority of the householder's education level is junior high school, most of them are farming. In order of people's consumption patterns', it goes: electricity、coal wood、solar energy. There are several variables includes per capita income of labor transfer, per capita net agriculture income, the range of household, education levels of the householder, per capita cultivated land area, consumption preference, which standard deviation larger relative. It's indicates the data variate greatly to some extent.

Table 1. Descriptive Statistics Variables $(N=288)$.

\begin{tabular}{|c|c|c|c|c|}
\hline variable & Mean & Standard deviation & Min & Max \\
\hline \multicolumn{5}{|l|}{ Dependent variable } \\
\hline Consumption of coal (kg/year) & 335.97 & 617.83 & 0 & 3000 \\
\hline \multicolumn{5}{|l|}{ Independent variable } \\
\hline Number of Labor Transfer & 1.09 & 0.97 & 0 & 5 \\
\hline Per capita income of labor transfer (yuan/year) & 13596.83 & 16406.54 & 0 & 100000 \\
\hline Income from labor transfer (yuan/year) & 13596.83 & 16406.54 & 0 & 100000 \\
\hline Number of Labor Transfer (with or without) & 0.70 & 0.46 & 0 & 1 \\
\hline Income from labor transfer (yes, no) & 0.70 & 0.46 & 0 & 1 \\
\hline \multicolumn{5}{|l|}{ Control variables } \\
\hline Per capita net agricultural income (yuan / year) & 11766.11 & 24239.71 & 0 & 370000 \\
\hline Family size (person) & 2.94 & 1.21 & 1 & 6 \\
\hline Education level of household head (years) & 8.45 & 3.01 & 0 & 16 \\
\hline Household age (years) & 48.85 & 10.28 & 21 & 76 \\
\hline Per capita cultivated land area $(\mathrm{mu})$ & 2.72 & 2.65 & 0 & 18 \\
\hline Coal price (yuan / jin) & 0.59 & 0.29 & 0.05 & 2.50 \\
\hline \multirow[t]{2}{*}{ Electricity price (yuan / degree) } & 0.52 & 0.03 & 0.45 & 0.61 \\
\hline & Count & Standard deviation & Min & $\operatorname{Max}$ \\
\hline Head of household occupation & 1 & 0.78 & 1 & 3 \\
\hline Consumer preferences & 3 & 1.71 & 1 & 8 \\
\hline
\end{tabular}

Source: June 2013, "labor transfer and rural living energy," a sample survey.

(2) Regression results

The regression model in the table 2 is the effect of labor transfer on total farmers coal consumption. The model 1 shows the regression results that the related variables of labor transfer on the household's coal consumption. The model 2, model 3 , model 4 , model 5 and model 6 added these control variables respectively, like households, basic economic characteristic, basic features, energy availability, price factor, consumer preference. The results show: the number of labor transfer increase, the household coal consumption reduce significantly; the increase of labor transfer income raises the household coal consumption. The proportion of labor transfer income to family income shows negative relation with the farmer's coal consumption. Per capita net agriculture income shows negative relation with the household coal consumption. The improvement of per capita cultivated land area (energy) significantly increases the household coal consumption. Consumption preference significantly increases annual consumption of coal.

Table 2. Labor Transfer against farmers coal consumption Regression Analysis $(N=288)$.

\begin{tabular}{|c|c|c|c|c|c|c|}
\hline variable & Model 1 & Model 2 & Model 3 & Model 4 & Model 5 & Model 6 \\
\hline Constant term & $145.78 * * *$ & $152.90 * * *$ & $286.59 * *$ & 82.04 & $498.43 *$ & $384.47^{+}$ \\
\hline \multicolumn{7}{|l|}{ Labor transfer } \\
\hline Number of Labor Transfer & $-37.11 *$ & $-38.29 *$ & $-35.40^{+}$ & $-39.26^{*}$ & $-30.29 *$ & $-27.55 *$ \\
\hline Per capita income of labor transfer & $0.01 *$ & $0.01 *$ & $0.01 *$ & $0.01^{+}$ & $0.01 *$ & $0.01 *$ \\
\hline $\begin{array}{l}\text { The proportion of income from labor transfer to total } \\
\text { household income } \\
\text { Basic Economic Characteristics of Households }\end{array}$ & -7.12 & -9.60 & -24.13 & -4.15 & -5.98 & -12.15 \\
\hline Net income per capita in agriculture & & -0.01 & -0.01 & $-0.01^{+}$ & -0.01 & -0.01 \\
\hline Family size & & & $-35.78 * *$ & -12.93 & -9.27 & -11.32 \\
\hline
\end{tabular}




\begin{tabular}{|c|c|c|c|c|c|c|}
\hline variable & Model 1 & Model 2 & Model 3 & Model 4 & Model 5 & Model 6 \\
\hline Head of household education level & & & $-9.78^{+}$ & -5.88 & -3.76 & -4.13 \\
\hline Age of head of household & & & 0.29 & 0.23 & -1.00 & -0.90 \\
\hline Head of household occupation & & & 28.56 & $39.01 *$ & 12.95 & 13.28 \\
\hline \multicolumn{7}{|l|}{ Energy availability } \\
\hline Per capita arable land & & & & $37.03 * * *$ & $33.15 * * *$ & $32.19 * * *$ \\
\hline \multicolumn{7}{|l|}{ Price factor } \\
\hline Coal prices & & & & & $371.93 * * *$ & $367.11^{* * *}$ \\
\hline Electricity prices & & & & & $-829.51 *$ & $-682.19^{+}$ \\
\hline Consumer preferences & & & & & & $12.36^{+}$ \\
\hline Pseudo $\mathrm{R}^{2}$ & 0.0198 & 0.0198 & 0.0701 & 0.2044 & 0.4774 & 0.4836 \\
\hline
\end{tabular}

Note: ${ }^{* * *} \mathrm{p}<0.001 ;{ }^{* *} \mathrm{p}<0.01 ;{ }^{*} \mathrm{p}<0.05 ;+\mathrm{p}<0.1$. Source: same as Table 1 .

Table 3 is the regression model of farmer's coal consumption for different income types, which are studied from the view of classifying farmers in Shannxi according to farmer's income contingent. Model 1 ', Model 2' and Model 3 'are the regression results of farmer household's labor-related variables on farmer's coal consumption, which is mainly based on agricultural income (net income per household is less than per capita labor income). Model 4 'and Model 5' are the regression results of the three variables of farmer's labor transfer, which is mainly based on the income of labor transfer (household per capita agricultural net income is less than the transfer income of per capita labor force), to farmers' coal consumption. All the sample of farmer households with labor-transferred income contain the amount of transferring labors and incomes, so we don't need to discuss the important of amount of transferring labors and incomes on household coal consumption. The results shows that there were positive correlations between labor force transfer and farmer's coal consumption, in the former case (based on agricultural income) and farmer's (the latter) whose income was mainly from labor transferred, the number of labor force transfer shows negative correlation with the farmer's coal consumption. There is a positive correlation between income from labor transfer and coal consumption of farmers, and the increase of labor transfer income raises the household coal consumption. Farmers whose labor transfer significantly increased its coal consumption, and labor transfer income significantly decreased its coal consumption. The former can significantly increase the household consumption of coal, while the latter can not significantly. The former increase the age of household can significantly increase the farmer's coal consumption, while the latter exact contrary. The per capita arable land changed from the former significantly positive correlation to the latter non-significantly. The increase of electricity price could significantly reduce the coal consumption of the farmer, while the increase of electricity price significantly improved farmer's coal consumption which is mainly based on the labor transfer income. The increase of the coal price with the net income of agriculture can significantly increase the consumption of coal in the household, while the increase of farmer's coal price can reduce the coal consumption significantly which based on the labor transfer income.

Table 3. Labor Transfer against coal consumption of households in different income types regression analysis.

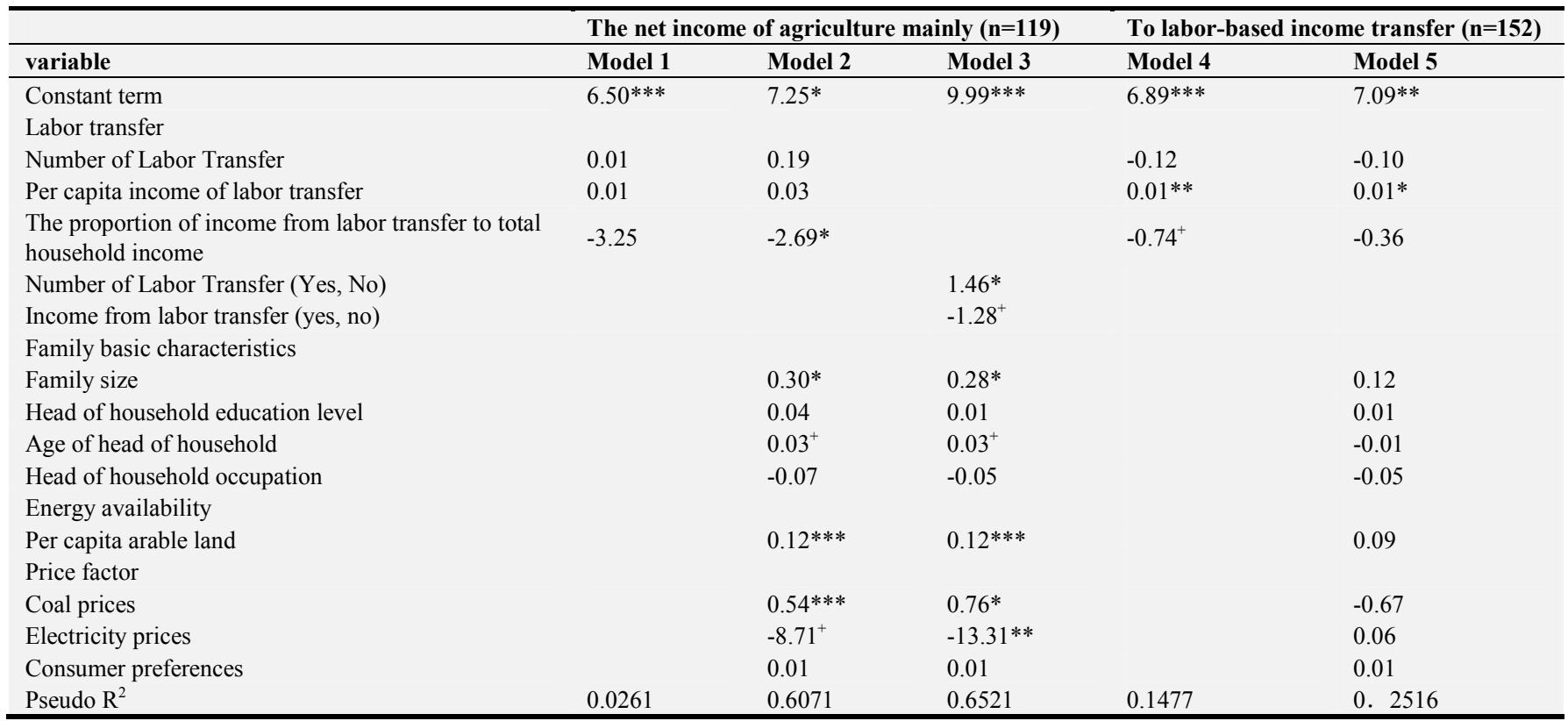

Note: $* * * \mathrm{p}<0.001 ; * * \mathrm{p}<0.01 ; * \mathrm{p}<0.05 ;+\mathrm{p}<0.1$ 。 Source: same as Table 1 . 


\section{(II)Discussion}

It can be seen from Table 2, the increase in the number of labor transfer can significantly reduce the consumption of coal in the household. Labor transfer reduced the resident population directly, and coal consumption with the population decreases. The increase in per capita income from labor transfer can significantly increase the consumption of coal. The more labor transfer income, the more income they are. However, in the view of the high initial cost of high quality commodities such as electricity and solar energy. The farmers will increase the consumption of coal commodities with relatively abundant resources. The proportion of labor transfer income to total household income is negatively correlated with the consumption of coal, which indicates that the higher the proportion of labor transfer income to total household income, the smaller the consumption of coal will be. It's connected with the overall economic situation, especially the increase of non-agricultural income. farmers' energy consumption structure has the same tendency from biomass energy to low-quality commodity energy to high-quality commodity energy. The higher energy availability (per capita arable land) will increase farmer's coal consumption. the larger area of cultivated land, the higher income of farmers. the stronger ability to purchase coal, the more coal consumption. Consumption preference has significantly positive correlation with the annual per capita consumption of coal.

From Table 3, the increase in the number of rural laborers with the main agricultural income can significantly increase the consumption of farm households, such as fuel wood and straw, which can be obtained from agriculture directly. There are small number of transfer and income. The labor force reduce farmer personal bring about the farmers overall consumption decreased, so farmers will consider increasing the use of coal energy. There was a negative correlation between the number of labor force transfer and the consumption of farmer households, which is basic on labor transfer income. Such farmers rely on the labor transfer income, with the increase number of transfer, their consumption attitudes change soon. people tend to use electricity and other clean energy, reduce coal consumption. The increase of farmer's income from labor transfer can significantly increase the consumption of farm households. that means, the more labor income from labor transfer, the more coal consumption will be. The more disposable income of farmers, the more coal consumption for they. In addition, consumer preferences have a significant impact on per capita consumption of coal, suggesting that individual consumption habits still play an important role in the consumption of commodity energy.

\section{Conclusion}

This article has used the real diagnosis analysis on the impact of labor transfer on rural households coal consumption. Main conclusions of the study are as follows:
1) The increase in the number of household labor transfers significantly reduces household energy consumption throughout the larger context; 2) The higher the income generated the greater farmers' ability to pay for their consumption. Accordingly the increase in household consumption is significantly; 3) Scale, energy availability and coal prices have a certain impact on farmers' coal consumption.

Therefore, this paper proposes to change the labor transfer to affect the consumption of coal, so as to better guide the farmers' energy consumption more effective. However, due to the inadequate use of coal and serious pollution, it is necessary to promote renewable energy widely, Increase the consumption of other high-quality consumable energy while increasing the consumption of coal in the household and enhance energy consumption by-products as useful resource. Through rational use of rich renewable resources in rural areas, it might help stave off environmental issues, and build a green low-carbon environment of rural energy consumption patterns, and promote China's new rural construction.

\section{Acknowledgements}

Fund Project: National Natural Science Foundation of China (71273206); Shaanxi Provincial Department of Education key scientific research plan (15JZ037); Shaanxi province social science sector major theory and reality problem research project (2017Z018)

\section{References}

[1] Chen Xiwen. the "Three Rural Issues" of Urbanization in China [J]. National School of Administration, 2012, 12. 4-13.

[2] Lv Jingye, Zhang Jinsuo, Lin Lipeng, Zhang Weifeng. Dynamic changes in China's carbon footprint energy consumption study $[\mathrm{J}]$. Xi'an University of Science and Technology, 2014, 09: 5-30.

[3] Tian Yishui. Energy situation and development trend of China's rural areas in 2013 [J]. Chinese Energy, 2014, 08: 10-14.

[4] Shao Chauchau, Chen Weimin. Study of urbanization impact on energy consumption mechanism [J]. Northwest Population, 2015, 03: 6-11.

[5] Liu Yuan, Zhou Chunfang. Non-agricultural employment of rural labor force and its impact on the rural economy and society - Taking Jiangsu Province Li Zhuang poor villages example $[\mathrm{J}]$. Study the Local Economic and Social Development, 2008: 124-132.

[6] Wang Jinxiu. Fundamental shift of rural labor force depends on Rural Education [J]. Journal of Jimei University (Education Science Edition), 2005, 06: 1-5.

[7] Stark, O. D. \& Bloom, E. The new economics of labor migration [J]. The American Economic Review, 1985, 75: 173-178.

[8] Chen Gang, Zhang Hui. Labor Migration effect on rural consumer market [J]. New Socialist Countryside and Advertising Industry Topics, 2010, 03: 4-11. 
[9] Lou BoJie. Farmer household energy consumption choices behavior study [D]. Chinese Academy of Agricultural Sciences, 2008.

[10] Foley, G. Pbotovoltaic Applications in the rural Areas of the Developing World [J]. World Bank Technical Paper Number 304, Energy Series, Washington, DC. 1995, 03: 32-35.

[11] Chantale Andre, Marlène Fortier, Michel Fournier. Immunotoxic potential of aeration lagoon effluents for the treatment of domestic and hospital wastewaters in the freshwater mussel Elliptio complanata [J]. Journal of Environmental Sciences, 2012, 05: 23-25.

[12] Li Zhenyu, Zhang Jinsuo, Zhu Lijia. Disaster chain effect of coal industry chain extension risk $[\mathrm{J}]$. Xi'an University of Science and Technology, 2011, 11:27-30.

[13] Zhang Cuiping. Impact on farmers payrolls energy consumption - in Taihu of Jiangsu Province [D]. Nanjing Agricultural University, 2009.

[14] Guo Chenxin. Labor Migration on the energy consumption of household [D]. Xi'an University of Science and Technology, 2014.

[15] Yang He. Study on the transfer of rural labor force in Liaoning [D]. Liaoning University, 2010.

[16] Su Benying, Zhang Lu, Li Yonggeng, Jiang Gaoming. Income of farmers improve effect on the energy consumption structure -- in Mentougou District of Beijing as an example [J]. Chinese Agricultural Science Bulletin, 2011, 04 (20): 420-426.

[17] Yu Bo. Analysis of household energy choices factors and the promotion of new energy policy implications Analysis - A Case Study of Nanjing, Jiangsu Province [D]. Nanjing Agricultural University, 2007. 